Supporting Information of

\title{
Selective Inclusion of Secondary Amine Guests in sH
}

\section{Hydrate Systems}

Jiwoong Seol*

Faculty of Liberal Education, Seoul National University, 1 Gwanak-ro, Gwanak-gu, Seoul 08826, Republic of

Korea

*Corresponding author: seoljiwoong@snu.ac.kr

\section{Table of contents}

$\begin{array}{ll}\text { Figure } S 1 . & \text { p.2 }\end{array}$ 


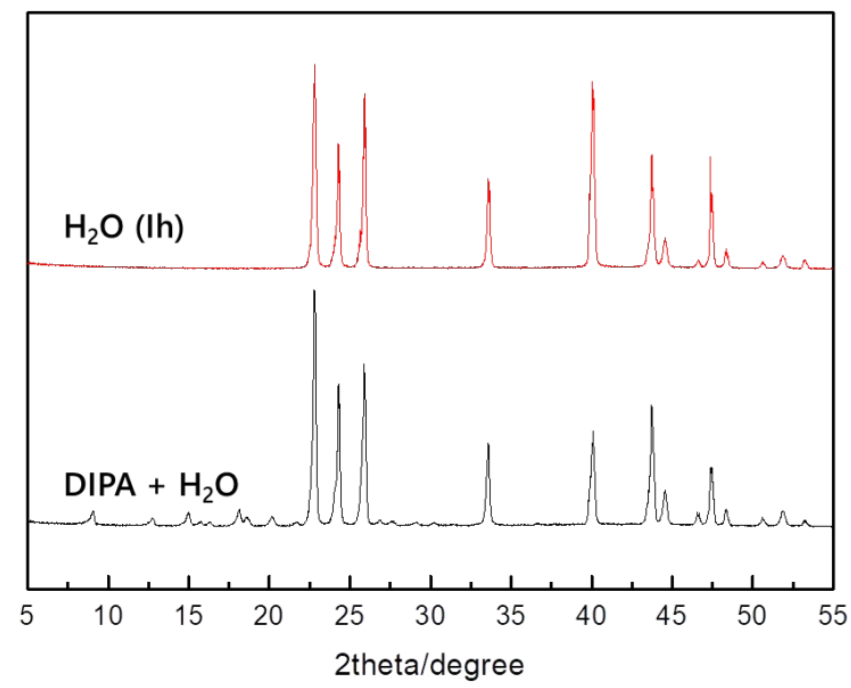

Figure S1. Powder x-ray diffraction patterns of the ice and DIPA $+\mathrm{H}_{2} \mathrm{O}$ samples (at $150 \mathrm{~K}$ ). 